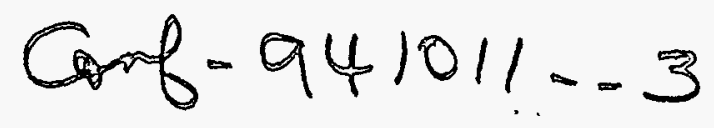

SAND93-2686C

\title{
EARLY RESULTS FROM AN EXPERIMENTAL PROGRAM TO DETERMINE THE BEHAVIOR OF CONTAINMENT PIPING PENETRATION BELLOWS SUBJECTED TO SEVERE ACCIDENT CONDITIONS ${ }^{1}$
}

\author{
SAND93-2686C
}

L. D. Lambert

M. B. Parks

\begin{abstract}
Containment piping penetration bellows are an integral part of the pressure boundary in steel containments in the United States (U.S.). Their purpose is to minimize loading on the containment shell caused by differential movement between the piping and the containment. This differential movement is typically caused by thermal gradients generated during startup and shutdown of the reactor, but can be caused by earthquake, a loss-of-coolant accident (LOCA), or "severe" accidents. In the event of a severe accident, the bellows would be subjected to pressure, temperature, and deflection well beyond the design basis.
\end{abstract}

Most bellows are installed such that they would be subjected to elevated internal pressure, elevated temperature, axial compression, and lateral deflection during a severe accident. A few bellows would be subjected to external pressure and axial elongation, as well as elevated temperature and lateral deflection. The purpose of this experimental program is to examine the potential for leakage of containment bellows during a severe accident.

The test series subjects bellows to various levels and combinations of internal pressure, elevated temperature, axial compression or elongation, and lateral deformation. The experiments are being conducted in two parts. For Part I, all bellows specimens are tested in "like-new" condition, without regard for the possible degrading effect of corrosion that has been observed in some containment piping bellows in the U.S. Part I testing, which included 13 bellows tests, has been completed. The second part of the experimental program, in which bellows are subjected to simulated corrosive environments prior to testing, has just just begun.

The Part I experiments have shown that bellows in "like-new" condition can withstand elevated temperatures and pressures along with large deformations before leaking. In most cases, the likenew bellows were fully compressed without developing any leakage. At the time of writing, the corroded bellows test program has just begun. If available, results from these tests will be presented at the conference.

MS 0744

P. O. Box 5800

Sandia National Laboratories

Albuquerque, NM 87185-0744

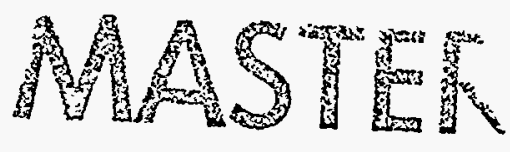

1This work was supported by the U.S. Nuclear Regulatory Commission and performed at Sandia National
Laboratories, which is operated by the Department of Energy under contract number DE-AC04-94AL85000. 


\section{DISCLAIMER}

Portions of this document may be illegible in electronic image products. Images are produced from the best available original document. 


\title{
EARLY RESULTS FROM AN EXPERIMENTAL PROGRAM TO DETERMINE THE BEHAVIOR OF CONTAINMENT PIPING PENETRATION BELLOWS SUBJECTED TO SEVERE ACCIDENT CONDITIONS
}

\author{
L. D. Lambert \\ M. B. Parks
}

\subsection{INTRODUCTION}

The bellows tests are part of the Containment Integrity Programs [1], which are being conducted at Sandia National Laboratories (SNL) under the sponsorship of the U. S. Nuclear Regulatory Commission (USNRC). The final goal of the Containment Integrity Programs is to generate a suite of validated methods that can be used to predict containment behavior under severe accident conditions. In pursuit of this goal, a series of scale model containment buildings have been tested to failure. The models were subjected to static internal overpressurization at ambient temperatures, with the response being monitored by a large number of sensors. The measured response was then compared with analytical results that were compiled both before and after the test, in order to verify the analytical methods. Additional containment model tests are being planned as a part of a cooperative program involving the Nuclear Power Engineering Corporation (NUPEC) of Japan, the USNRC, and SNL [2].

Because of the limited number and scale of the containment models, separate programs have been conducted to further investigate the severe accident behavior of containment penetrations.

Electrical penetration assemblies, compression seals and gaskets, inflatable seals, personnel airlocks, and equipment hatches have been tested. The ongoing bellows experiments are a part of the containment penetration test series.

\subsection{Background and Motivation for the Experimental Program}

Containment piping penetration bellows are primarily used in steel containments, with only limited use in reinforced and prestressed concrete containments. An example of a typical containment process piping bellows is illustrated in Figure 1. Process piping bellows are employed in both PWR and BWR containments. In addition to process piping penetrations, bellows are also used at the penetration of vent lines into the suppression chamber of BWR, Mk-I containments. Process piping bellows range in size from 6 to 60 inches in diameter while vent line bellows vary from 65 to 125 inches in diameter.

All known containment bellows in the U.S. are constructed from SA240, type 304 stainless steel. The bellows are formed from annealed sheet material; however, they are not annealed after forming. Process piping bellows are normally constructed of two plies of stainless steel sheets that are separated by a thin wire mesh ( $\sim 0.010$-inch wire diameter). The redundant outer ply provides a means to check for leakage of the bellows by pressurizing the space between plies and noting any drop in pressure. In contrast with process piping bellows, the majority of vent line bellows are one-ply; approximately $10 \%$ are two-ply. The thickness of the individual plies ranges from about $0.020 \mathrm{inch}$ to as much as 0.100 inch for the large diameter vent line bellows [3]. 
In most cases the bellows are located "outside" the containment wall, as shown in Figure 1, such that outward movement of the containment shell will compress the bellows. Note also that the bellows is exposed to the same internal pressure and temperature environment as the containment. Vertical growth of the containment, due to thermal expansion and/or the pressure uplift on the containment dome, imposes a lateral or shear type of deformation on the bellows. Thus, there are four primary loading conditions for which these types of containment bellows could be exposed: internal pressure, elevated temperature, axial compression, and lateral deformation.

In a few cases, bellows are located "inside" the containment shell, which tends to reverse some of the applied loadings from the containment. For example, the containment pressure would act on this type of bellows because an external pressure and outward movement of the containment would actually elongate the bellows instead of compressing them. In all known applications, the bellows are an integral part of the containment pressure boundary, such that leakage though the bellows would compromise the functional integrity of the containment pressure boundary.

The purpose of bellows is to minimize the loadings imposed on the containment shell caused by differential movement between the pipe and the containment wall. This differential movement is normally caused by thermal gradients during startup and shutdown of the reactor. The bellows are designed to accommodate the differential movements caused by a loss-of-coolant accident (LOCA) and/or a safe shutdown earthquake (SSE). The design standards are provided by the Expansion Joint Manufacturers Association (EJMA) [4]. Normally, bellows are conservatively designed to withstand about 5000 cycles of design-basis loading, although they typically experience only a few minimal cycles due to startup and shutdown of the reactor. Therefore, it would appear that bellows design is quite conservative for normal containment operating conditions. However, significant, integrity-threatening bellows loadings can be caused by accidents that exceed the design basis, such as could occur during the so-called "severe" accident. The response of bellows to severe accident types of loadings is the focus of the this research program.

In the event of a severe accident, the bellows could be subjected to pressure, temperature, and deflections well beyond the design basis. A qualitative example of the loadings that could be imposed on a bellows that would be compressed during a severe accident is illustrated in Figure 2. As shown, the axial displacement of the bellows would be relatively small until the containment yields in the circumferential or "hoop" direction. After yielding, the axial displacement per unit change in pressure would increase at a much faster rate, such that the bellows would be fully compressed by the outward movement of the containment shell. (Finite element analyses of an actual containment have shown that it is possible for some containment bellows to become fully compressed before failure of the containment shell is predicted.)

Once full compression is achieved, it is very likely that a leak would develop. One potential source of leakage could occur as a result of the end spools cutting through the thin bellows material. Another likely leak path would be failure of the connection of the end spools to the piping, since these connections were not designed for transferring the movement (loading) of the containment shell directly to the piping. In any event, an obvious "limit state" for the bellows would seem to be when they reach full compression. The primary question to be answered is: "Are containment bellows capable of reaching the point of full compression without leaking?"

This question becomes more complex when the variety of possible load combinations are considered, since the bellows will be simultaneously subjected to axial compression, lateral deformation, internal pressure, and elevated temperature. The pursuit of an answer to this question began with a review of past research programs and a survey of containment bellows applications. Finite-element analyses of a typical containment bellows were also conducted in order to assess the 
ability of bellows to remain leaktight during a severe accident. In short, these efforts did not locate any past bellows research that provided significant insight into the ultimate behavior of bellows subjected to severe accident loadings. Also, the analytical methods were unable to model the bellows at the large deformations required for bellows failure [5]. Therefore, an experimental program was designed to develop a database for assessing the leaktight capacity of containment bellows.

\subsection{Some Notes on the Development of the Bellows Test Program}

The intent of the bellows test program is to learn as much as possible about the effects of different bellows geometries and loading conditions on failure of containment bellows. Because of finite resources, all possible bellows designs and loadings could not be examined. An attempt was made to design test specimens that "bound" the different types of bellows geometries used in U.S. containments and to apply "worst-case" types of bellows loadings that might occur in a severe accident. In this way, data would be obtained for evaluating the loading limits which bellows could be expected to withstand before developing leakage.

Because of the insignificant number and magnitude of loading cycles during normal operating conditions, it was decided that the test program would not attempt to replicate the effects of repeated, normal operating types of loadings on the bellows specimens. In other words, no consideration of fatigue damage is made or believed to be warranted.

Because a torsional type of loading would not be applied to the bellows from the containment in the event of a severe accident, torsional loadings were not considered in this test program. The program only investigated the effects of pressure, temperature, and axial and lateral deformation. It is possible for bellows to experience torsional loading from the piping during a severe accident. However, to include this type of loading would have added considerably to the cost of this project and thus was deemed to be beyond the scope of the current study. Also, bellows have been previously tested in torsion, as reported in Reference 6.

The material properties of type 304 stainless steel, which is used in containment bellows construction, degrades with increasing temperature, as shown in Figure 3 . The data used to develop Figure 3 were taken from References 7-10 and verified by independent tests conducted at SNL. The loss of elongation (or "ductility") causes particular concern since the ability of bellows to remain leaktight while subjected to large deformation is highly dependent on the amount of ductility in the bellows material. For this reason, some of the bellows tests are conducted at elevated temperature. Other similar tests were conducted at room temperature in order to evaluate the effect of elevated temperature on bellows behavior. The elevated temperature tests are conducted at $425 \pm 25^{\circ} \mathrm{F}$ for several reasons. The primary reason is that the loss of ductility apparently stabilizes at about $400^{\circ} \mathrm{F}$ without significant additional reduction at higher temperatures. Another reason is that this temperature can be safely achieved using hot oil without a severe fire danger. The estimate of $400^{\circ} \mathrm{F}$ is also a reasonable estimate of a possible bellows temperature in the event of a severe accident.

Another important consideration in determining ultimate bellows behavior is the condition of the bellows prior to testing. In Part I of the test program, all bellows specimens were tested in "likenew" condition. The investigation of bellows in like-new condition was the original focus of the experimental program. However, because bellows specimens in like-new condition performed extremely well during testing under severe accident conditions, the decision was made to expand the scope of the test program to include corroded bellows. Significant corrosion damage has been discovered in some containment bellows in actual plants. The corrosion was discovered during 
routine leak rate testing of the containment. In some cases, the corrosion was severe enough that the bellows could not pass the leak rate requirements and thus these bellows were replaced. Part II of the bellows program has been designed to gather information on the degrading effects of corrosion on the ability of bellows to remain leaktight during a severe accident. The bellows specimens in this test series are submersed in a high concentration of magnesium chloride in order to produce transgranular stress corrosion similar to that observed in actual plants. The goal is to stop the corrosive process just before the bellows would begin to leak. In this way, bellows specimens that are capable of passing leak rate tests, and thus remaining in service, could be tested to determine the effects of corrosion on the ability of bellows to withstand large deformations without leakage.

At the time of writing, all thirteen of the like-new bellows tests have been completed. However, the corrosion test program has just begun. Thus, only the results of like-new bellows tests are described in this paper. A description of the test specimens, the conduct of the various tests, the test results to date, and a summary of the findings and early recommendations are provided in the remainder of the paper.

\subsection{TEST SPECIMENS}

All bellows specimens were fabricated to nuclear specifications by a supplier of nuclear grade bellows.

Bellows specimen geometries were selected after a lengthy search to determine the types most frequently used by the nuclear power industry, and to derive a representative cross-section of those types. An effort was made to include extremes in numbers of convolutions, depth of convolutions, ratio of convolution depth to ply thickness, and universal versus single-element bellows (see Figure 4).

The geometry of the bellows specimens is provided in Table 1. Figure 5 defines the bellows convolution parameters listed in Table 1. All of the bellows specimens were constructed of type 304 stainless steel. The sheet material from which the bellows were formed was annealed. In the fabrication of a bellows, a flat stainless steel sheet is first rolled into a cylindrical shape and welded; then the convolutions are cold-formed. The bellows specimens were not annealed after forming.

The bellows specimens are divided into two broad categories. Phase I specimens are designed to be "generic," incorporating a variety of bellows features found in actual containment bellows, while Phase II specimens are representative of specific bellows geometries found in actual containments.

\subsection{DESCRIPTION OF TESTS}

All testing may be considered "pseudo-static," with each test requiring a few hours to complete. Pressure and deformation loadings were applied in steps followed by hold periods to allow collection of data, unless otherwise noted. The bellows in the elevated temperature tests were preheated in the range of $425 \pm 25^{\circ} \mathrm{F}$ and held in this range from start to finish of the tests.

Leakage of the bellows specimens is mainly a qualitative indication. In the case of ambient temperature tests, leakage is determined by a flow indication from flowmeters that monitor the pressurizing line to the interior volume of the specimen, and, in cases of two-ply bellows, the 
pressurizing line to the space between the two plies. In the case of elevated temperature tests, leakage is determined by visually monitoring the bellows for any loss of the heated oil that is used to pressurize the bellows.

Instrumentation used in the tests included a limited number of strain gages (normally 9 gages per test, only on ambient temperature tests), thermocouples to ensure that the desired test temperature was achieved, flowmeters to measure leakage between plies, displacement transducers to record the applied axial and lateral deformation, load cells, and pressure gages. Extensive photographic coverage of the tests was also used to record the deformed shape of the bellows for various applied loadings.

Initially, the plan was to test all twenty of the specimens in Table 1 in "like-new" condition without consideration for the possible degrading effects of corrosion. However, because the bellows performed very well in "like-new" condition, it was later decided to limit the number of these tests to thirteen, with the remaining seven specimens to be tested after being subjected to corrosion.

\subsection{Part I - Tests of "Like-New" Bellows}

\subsubsection{Test Procedure}

The initial series of thirteen tests were all conducted using bellows in "like-new" condition. There were 11 tests of Phase I specimens and 2 tests of Phase II specimens. Tests of Phase I specimens are intended to determine which of nine different geometries are more likely to leak when subjected to severe accident conditions, and to determine the capacity of bellows in general. Table 2 provides a description of the Phase I tests.

Phase II specimens are representative of specific bellows geometries, with one of the specimens representing approximately 1:4 - scale vent line bellows (VL-2 specimen) in a BWR Mark - I and the other one being representative of a full-sized process piping bellows (PP-2 specimen) in a PWR containment. Both the PP-2 and VL-2 specimens were tested at elevated temperature in the range of $425 \pm 25^{\circ} \mathrm{F}$. The PP-2 load combinations of internal pressure, axial compression, and lateral deformation were based on deformations from an axisymmetric finite element analyses of an actual containment at the elevation of the bellows that this specimen is intended to represent. At full compression, the applied load combination was $74 \mathrm{psig}, 2.5$ inches lateral, and 11.3 inches axial compression. The VL-2 specimen was loaded similarly to the SCT load combination described in Table 2, except that the maximum lateral deformation was only 1 inch when the maximum internal pressure of 150 psig was reached.

If leakage did not occur during the first load cycle of the above tests, the bellows were subjected to additional loadings until a leak finally developed. The types of additional loadings varied from test to test. For the tests in which the bellows were compressed, the bellows were reloaded in the same manner as in the first loading cycle up to the point of full compression. If leakage still did not occur, the shear deformation was further increased until a tear developed in the bellows. For elongation tests, the bellows were unloaded after reaching full elongation and then reloaded until leakage occurred.

\section{DISCLAIMER}

This report was prepared as an account of work sponsored by an agency of the United States Government. Neither the United States Government nor any agency thereof, nor any of their employees, makes any warranty, express or implied, or assumes any legal liability or responsibility for the accuracy, completeness, or usefulness of any information, apparatus, product, or process disclosed, or represents that its use would not infringe privately owned rights. Reference herein to any specific commercial product, process, or service by trade name, trademark, manufacturer, or otherwise does not necessarily constitute or imply its endorsement, recommendation, or favoring by the United States Government or any agency thereof. The views and opinions of authors expressed herein do not necessarily state or reflect those of the United States Government or any agency thereof. 


\subsubsection{Evaluation of "Like-New" Test Results}

\section{Compression Tests}

A summary of the like-new bellows test results is provided in Table 3. In all cases, the bellows that were subjected to axial compression and lateral deflection remained leaktight up to, or very near, the point of full compression. Full compression is defined as the point at which all the convolutions and the end spools are in metal-to-metal contact. Bellows that were tested at elevated temperature failed earlier in the loading cycle than bellows tested at room temperature. Also, bellows with deeper convolutions developed leakage earlier in the loading cycle than bellows with shallower convolutions. However, the deepest convolution bellows at $400^{\circ} \mathrm{F}$ were more than $85 \%$ compressed at the start of leakage. This occurred in spite of the bellows being simultaneously subjected to combinations of internal pressure, elevated temperature, and lateral deformation.

Figure 6 provides photographs taken of Test I-3-SC at four loading steps during the initial compression load cycle. The upper left-hand photo 6(a) shows the bellows before any loads were applied. The undeformed length of the bellows was 5 inches. Photo $6(\mathrm{~b})$ shows the bellows when the axial and lateral displacements reached 1-7/8 inches and 7/8 inch, respectively. At this point the bellows are about $40 \%$ compressed. In Photo $6(\mathrm{c})$ the loadings have been further increased to axial and lateral displacements of 3 inches and 1-3/8 inches, respectively, which corresponds to $64 \%$ compression. The bellows are shown in $6(\mathrm{~d})$ after reaching $100 \%$ (full) compression. Applied loadings at this point resulted in axial and lateral displacements of 4-3/4 inches and 2-1/4 inches, respectively. Note that, in spite of the extremely large deformations, the bellows remained leaktight. Leakage did not occur until the loadings were reversed. That is, leakage did not occur until the bellows was displaced in the opposite direction toward the initial unloaded condition.

Sharp creases in the bellows convolutions developed as the bellows were subjected to large axial compression combined with lateral deformation. The usual source of initial leakage in all the compression tests was small tears that developed at the "point" of the creases. Examples of two such tears are shown in Figures 7 and 8.

\section{Elongation Tests}

Table 3 also provides a summary of the results of the like-new elongation tests. Most of these specimens were fully elongated to the point where all the convolutions were flattened into a cylinder before developing a leak. The bellows were capable of this extreme elongation even though they were simultaneously subjected to worst-case lateral deformations. However, it should be noted that actual containment bellows that would be elongated during a severe accident would also be subjected to external pressure and elevated temperature.

External pressure and elevated temperature were not applied during these tests, the primary reason being that typical containment bellows can be extended to two to three times their original length before becoming fully elongated, with all convolutions being drawn back into a cylinder. Therefore, a given bellows can normally be expanded to greater lengths before reaching full elongation than it can be compressed before reaching full compression. Other reasons for not including external pressure and elevated temperature include the complexity and costs that it would have added to the program and the limited number of actual bellows that would be subjected to this loading condition. Further evaluation would be necessary to determine the effect of external pressure and elevated temperature, combined with elongation and lateral deformation, on the leaktight capacity of containment bellows. 
A sequence of photos taken during test I-16-SE is provided in Figure 9. The undeformed bellows was about 5 inches long before testing. The calculated length at full elongation is 17 inches. The upper left-hand photo (a) was taken of the bellows before loading. Photo 9(b) was taken when the bellows was about $37 \%$ elongated with a lateral deformation of $3 / 4$ inch. The bellows was $77 \%$ elongated with a lateral deformation of 1-1/2 inches in photo 9(c). Photo 9(d) shows the bellows when fully elongated at a lateral deformation of 2 inches. Note that at this point the bellows was leaktight, even though the bellows convolutions had all collapsed back into the cylinder from which they were formed. Small buckles, which appear as "wrinkles" in the bellows material, occurred as the convolution crests popped, literally, from their as-formed diameter back to the inner diameter of the bellows. Leakage normally occurred as the bellows material tore at the sharp point of one of these wrinkles. This usually happened during the unloading process as the bellows was being moved back to its original position. An example of such a tear is shown in Figure 10.

\subsection{Part II - Tests of Corroded Bellows}

Seven additional tests are planned for bellows that have been subjected to corrosion. The specimens will first be subjected to a simulated corrosive environment in order to produce transgranular stress corrosion similar to that observed in some containment bellows. The specimens will then be subjected to the same types of loadings as in the earlier tests of like-new bellows.

The planned seven test specimens are listed in Table 1. Phase I tests will be conducted following the same procedures described in Table 2. The VL-1 and PP-1 Phase II specimens will be tested following the same procedures as described above for the like-new VL-2 and PP-2 specimens, respectively. At the time of writing, the corroded bellows test program has just begun. If available, results from these tests will be presented at the conference.

\subsection{CONCLUSIONS/RECOMMENDATIONS BASED ON COMPLETED "LIKE- NEW" TESTS}

First, it must be noted that only the results of like-new bellows specimen tests have been presented. The degrading effects of corrosion on the ability of bellows to remain leaktight has not yet been examined. Therefore, the conclusions drawn here are only appropriate for bellows that have not been degraded in any way by corrosion.

Also, the reported results should not be "blindly" extrapolated for all like-new containment bellows. One must determine if the bellows in the containment in question fall within the parameters of the bellows that have been tested in this program. Of particular concern should be the type of material, the extent of corrosion, number and depth of convolutions, ply thickness and number of plies, type of bellows (universal or single), as well as the relative loading conditions of pressure, temperature, lateral deformation, and possibly others. The intent of the like-new bellows tests was to cover as wide a range of bellows geometries and loadings as possible; however, there may be some actual bellows that are not covered by these tests. Engineering judgment will likely be needed in the final assessment of whether these tests are applicable to a given situation.

If it is deemed that the test results for the like-new bellows are applicable, the following approach is recommended to estimate when leakage might occur in bellows that would be compressed during a severe accident. First, a nonlinear, axisymmetric or three-dimensional analysis of the containment should be performed to determine the expansion of the containment shell as a function of internal pressure and temperature at the location of penetration bellows. A conservative 
assumption would be to assume the bellows will leak when the axial compression reaches $75 \%$ of the deformation necessary to cause full compression.

For bellows that are elongated as a result of severe accident conditions, no specific recommendations can be made without further consideration of the effects of external pressure and elevated temperatures.

\subsection{SUMMARY}

A test program is under way to investigate the behavior of containment piping bellows when they are subjected to pressure, temperature, and deformation loadings that exceed their design bases. Thirteen tests have been performed of bellows in like-new condition, while another seven tests are planned to examine the effect of corrosion. The completed tests of like-new bellows have shown that bellows without corrosion are capable of withstanding very large deformations without leaking. The remaining tests of corroded bellows will be useful in assessing the degrading effects of corrosion on the ability of bellows to remain leaktight during a severe accident.

\subsection{REFERENCES}

[1] M. B. Parks et al., "Summary of NRC-Sponsored Research on Containment Integrity," Transactions of the Eleventh Conference on Structural Mechanics in Reactor Technology, Tokyo, Japan, 1991.

[2] K. Takumi et al., "Plan on Test to Failure of a Steel, a Pre-stressed Concrete, and a Reinforced Concrete Containment Vessel Model," Transactions of the Third International Conference on Containment Design and Operation, Toronto, Canada, 1994.

[3] M. H. Shackelford et al., Characterization of Nuclear Reactor Containment Penetrations, NUREG/CR-3855, SAND84-7180, Sandia National Laboratories, Albuquerque, NM, 1985.

[4] Standards of the Expansion Joint Manufactures Association, Inc., 5th Edition (1985 addenda), EJMA, Inc., 25 North Broadway, Tarrytown, NY.

[5] L. Greimann et al., Analysis of Bellows Expansion Joints in the Sequoyah Containment, NUREG/CR-5561, SAND90-7020, Sandia National Laboratories, Albuquerque, NM, December 1991.

[6] Rieger, W., "Torsion of Expansion joints - First Information and Test Results for Stability Properties and Behavior Under Stress," Transactions of the Seventh International Conference on Structural Mechanics in Reactor Technology, Vol. J, pp. 331-338, 1983.

[7] Nuclear Systems Materials Handbook, Vol. 1, Design Data, TID 26666 Vol. 1, Oak Ridge National Laboratory, Oak Ridge, TN.

[8] Aerospace Structural Metals Handbook, Vol. 2, Code 1303 (304 Stainless Steel), Battelle Columbus Laboratories, March 1973. 
[9] Henry J. Rack et al., An Assessment of Stress- Strain Data Suitable for Finite-Element Elastic-Plastic Analysis of Shipping Containers, NUREG/CR-0481, SAND77-1872, Sandia National Laboratories, Albuquerque, NM, September 1978.

[10] Peckner and Bernstein (eds.), Handbook of Stainless Steels, , McGraw-Hill, New York, 1977. 
Table 1: Bellows Test Specimen Data

\begin{tabular}{|c|c|c|c|c|c|c|c|c|c|}
\hline $\begin{array}{l}\text { pecimen } \\
\text { I.D. }\end{array}$ & Number & $\begin{array}{c}\text { Inner } \\
\text { Diameter } \\
\mathbf{d}_{\mathbf{i}} \text { (in.) }\end{array}$ & $\begin{array}{c}\text { Number of } \\
\text { Convolutions } \\
\underline{N}\end{array}$ & $\begin{array}{l}\text { Number of } \\
\text { Plies, n }\end{array}$ & $\begin{array}{c}\text { Ply } \\
\text { Thickness } \\
\text { t (in.) }\end{array}$ & $\begin{array}{c}\text { Convolution } \\
\text { Depth } \\
\text { w (in.) }\end{array}$ & $\begin{array}{c}\text { Convolution } \\
\text { Pitch } \\
\text { q (in.) }\end{array}$ & $\begin{array}{c}\text { End } \\
\text { Tangent } \\
\text { lt__in.) }\end{array}$ & $\begin{array}{c}\text { Center } \\
\text { Spool } \\
\text { Lc (in.) }\end{array}$ \\
\hline
\end{tabular}

\section{New Phase I:}

$\begin{array}{cll}\text { A-8-2 } & 3 & 12.00 \\ \text { A-8-2-e } & 1 & 12.00 \\ \text { A-8-1-e } & 1 & 12.00 \\ \text { B-8-2 } & 2 & 12.00 \\ \text { B-8-2-e } & 1 & 12.00 \\ \text { B-8-1-e } & 1 & 12.00 \\ \text { B-12-2 } & 2 & 12.00\end{array}$

8
8
8
8
8
8
12

0.020
0.020
0.020
0.020
0.020
0.020
0.020

0.50
0.50
0.50
1.25
1.25
1.25
1.25

0.50
0.50
0.50
0.75
0.75
0.75
0.75

\subsection{0}

$$
\begin{aligned}
& 1.00 \\
& 1.00
\end{aligned}
$$$$
1.00
$$$$
1.00
$$$$
1.00
$$

New Phase II:

$\begin{array}{lll}\text { PP-2 } & 1 & 19.25 \\ \text { VL-2 } & 1 & 19.25\end{array}$

6
4

0.031

1.50

0.020

0.50

1.00

0.50

2.00

9.50
3.00

Corroded Phase I:

$\begin{array}{lll}\text { A-8-2 } & 1 & 12.00 \\ \text { A-12-2 } & 2 & 12.00 \\ \text { C-6-2 } & 1 & 12.00 \\ \text { D-6-2 } & 1 & 12.00\end{array}$

D-6-2

8
12
6
6

0.020
0.020
0.020
0.020

0.5
0.5
0.5
1.25

\subsection{0}

0.50

0.50

0.75

1.00
1.00
1.00
1.00

Single

Single

4.00

Corroded Phase II:

PP-1 1

19.25

PP-1
VL-1

19.25

6

0.031

0.020

1.5

1.00

0.50

2.00

9.50

Specimen I.D. numbers in Phase I tests denote the bellows construction. The first letter (A, B, C,or D) indicates convolution depth ( $A$ or $C=0.5$ in., B or $D=1.25$ in.). The first number indicates the number of convolutions $(6,8$ or 12$)$, and the second number indicates one or two plies.

${ }^{*}$ Specimens A and B are single bellows. Specimens C, D, PP (process piping) and VL (vent line) are universal (see Figure 4) bellows.

** " $e$ " indicates that the end tangent shall be attached to the outer diameter of the end spool for these specimens (total 4 ). All other details of the connection are the same as shown in Figure 5 . 
Table 2

Description of Phase I Tests

Test No.

Specimen I.D.

Test Designation

Maximum Test

Pressure (psig)

\section{Like-New Tests:}

Compression:

2
3
4
9
10
11
12

Elongation:

13

14

15

16

A-8-2

B-8-2

B-8-2

B-12-2

B-12-2

A-8-2

A-8-2

SCT

150

$\mathrm{SC}$

SCT

SC

SCT

CL

LC

75

75

75

75

ambient

ambient

A-8-1-e

SE

SE

SE

B-8-1-e

B-8-2-e

SE

ambient

ambient

ambient

ambient

\section{Corrosion Tests:}

Compression:

1
5
6
7
8

A-8-2

SCT

150

C-6-2

D-6-2

SCT

150

SCT

75

A-12-2

SC

150

A-12-2

SCT

150

\section{Test \\ Designation \\ Description}

CL Axially compress the bellows until all convolution roots are fully compressed. If the bellows are still leaktight, apply lateral deformation until a tear in the bellows occurs. No internal pressure will be applied during this test.

LC Apply lateral offset until the bellows become unstable (i.e., a very small increase in lateral load produces relatively large lateral deformation). If the bellows are still intact, apply axial compression until all convolutions are fully compressed. If the bellows are still intact after being fully compressed, apply additional lateral deformation until a tear develops in the bellows. No internal pressure will be applied during this test. 
Table 2

Description of Phase I Tests

(Cont.)

SC Simultaneously apply internal pressure, axial compression and lateral deformation. Internal pressure, axial compression and lateral deformation shall be increased linearly such that the internal pressure reaches the maximum test pressure level in Table 2 when the total applied lateral deformation is 2 inches* when the bellows are fully compressed. If the bellows are still intact after being fully compressed, reverse the applied test conditions by removing axial and lateral deformation as well as internal pressure at the same rate at which each was originally applied. Continue unloading until either a crack develops or until all originally applied displacement and pressure has been removed.

SCT Same as SC except test temperature is $425 \pm 25^{\circ} \mathrm{F}$ throughout the specimen for the entire test.

SE Simultaneously apply axial elongation and lateral deformation. Axial elongation and lateral deformation shall be increased linearly such that the total applied lateral deformation is 2 inches when the bellows are fully elongated. If the bellows are still leak tight after being fully elongated, reverse the applied test conditions by removing elongation and lateral deformation at the same rate at which each was originally applied. Continue this process until either a crack develops or until all originally applied deflection has been removed. No internal pressure will be applied during this test.

\footnotetext{
* A lateral displacement of 2 inches is a conservative estimate of the amount of vertical displacement that a containment building would experience during a severe accident. Also, the spacing between the pipe and the opening in the containment is usually less than 2 inches (which limits the amount of lateral displacement of the pipe).
} 
Table 3

Bellows Failure Conditions

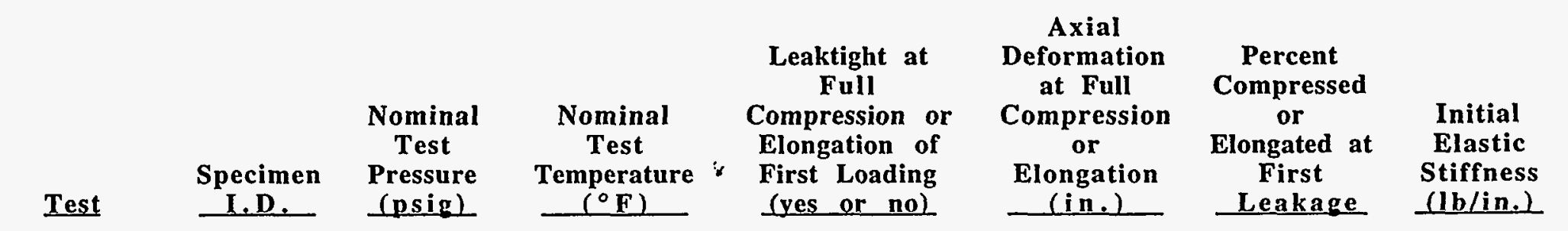

\section{Compression}

Tests:

I-11-CL A-8-2-1

I-12-LC A-8-2-2

I-3-SC B-8-2-1

I-4-SCT B-8-2-2

I-2-SCT A-8-2-3

I-10-SCT B-12-2-1

I-9-SC B-12-2-2

II-19 VL-2

Ambient
Ambient
75
65
150
68
72
150
74

Ambient
Ambient
Ambient
415
420
410
Ambient
415
400

yes
yes
yes
no
yes
no
no
yes
yes

3-1/4

$3-3 / 8$

$4-3 / 4$

$5-3 / 8$

3-3/4

$8-1 / 8$

$8-1 / 2$

3

$10-1 / 2$

Leakage

(lb/in.)

\section{Elongation}

Tests:

$\begin{array}{llll}\text { I-13-SE } & \text { A-8-1-e } & \text { Ambient } & \text { Ambient } \\ \text { I-14-SE } & \text { A-8-2-e } & \text { Ambient } & \text { Ambient } \\ \text { I-15-SE } & \text { B-8-1-e } & \text { Ambient } & \text { Ambient } \\ \text { I-16-SE } & \text { B-8-2-e } & \text { Ambient } & \text { Ambient }\end{array}$

no
yes
yes
yes

$6-1 / 2$
-6
-17
-18




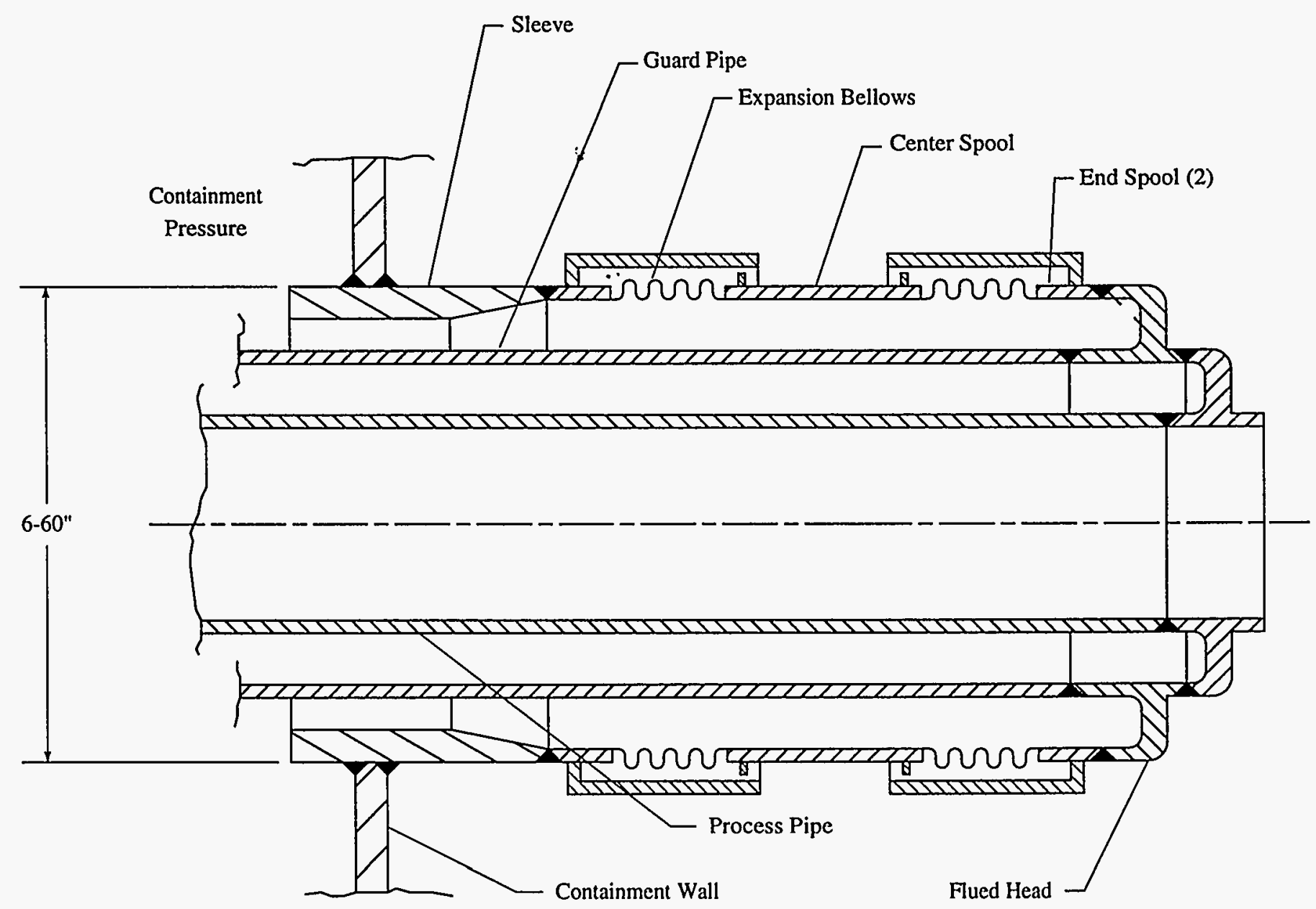

Figure 1: Typical Process Piping Bellows Configuration 


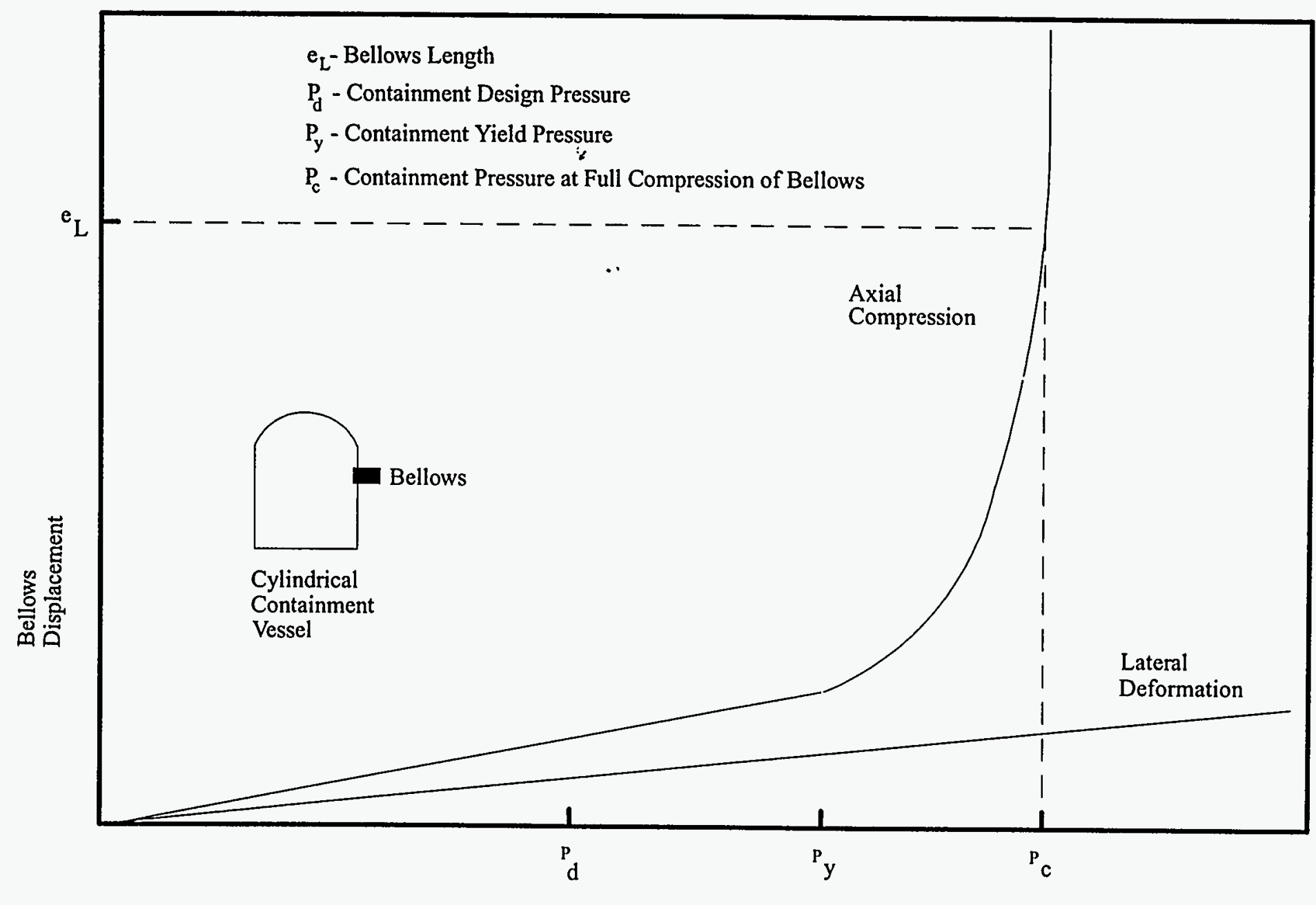

Containment Pressure

Figure 2. Potential Containment Bellows Loadings During a Severe Accident 


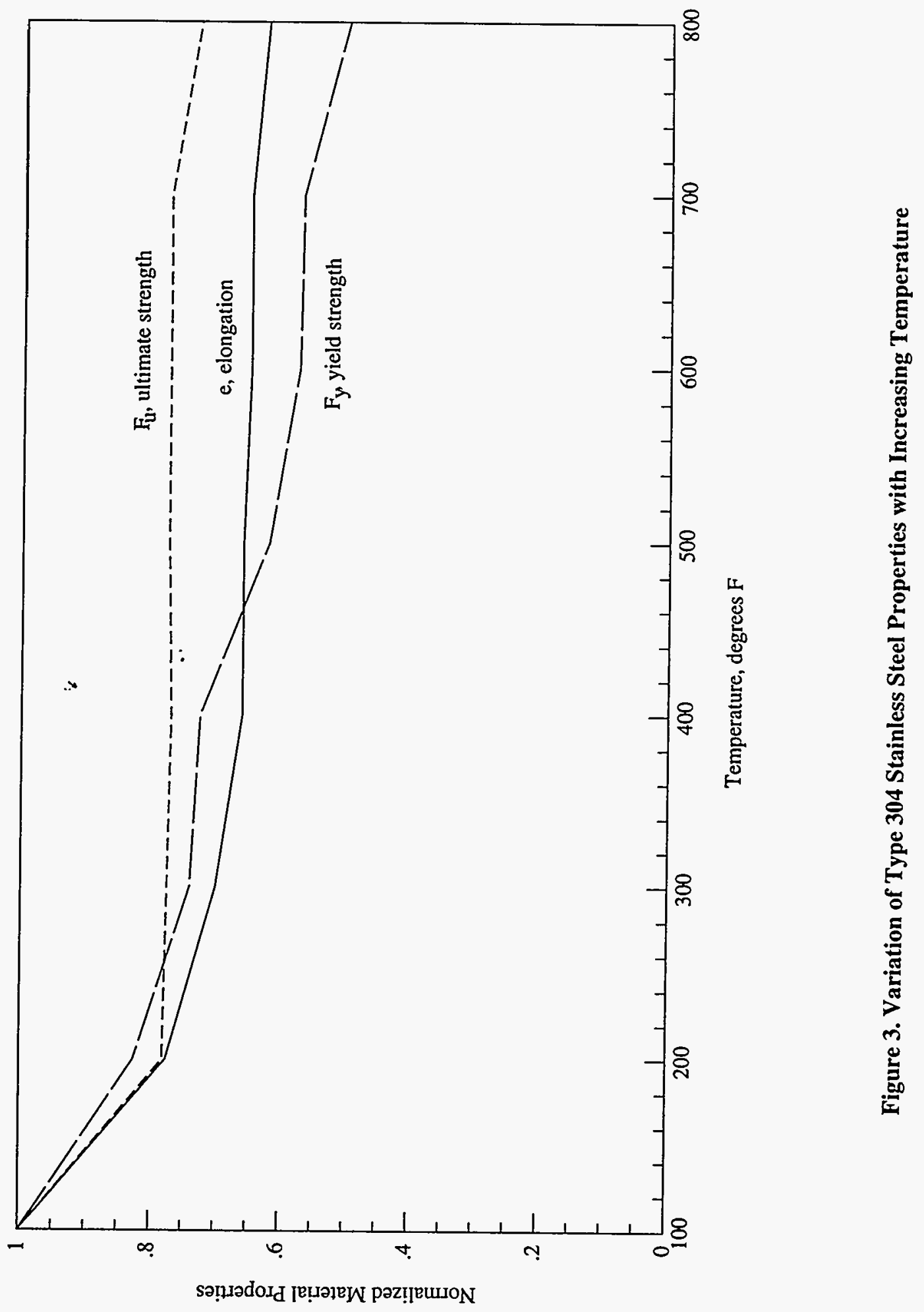




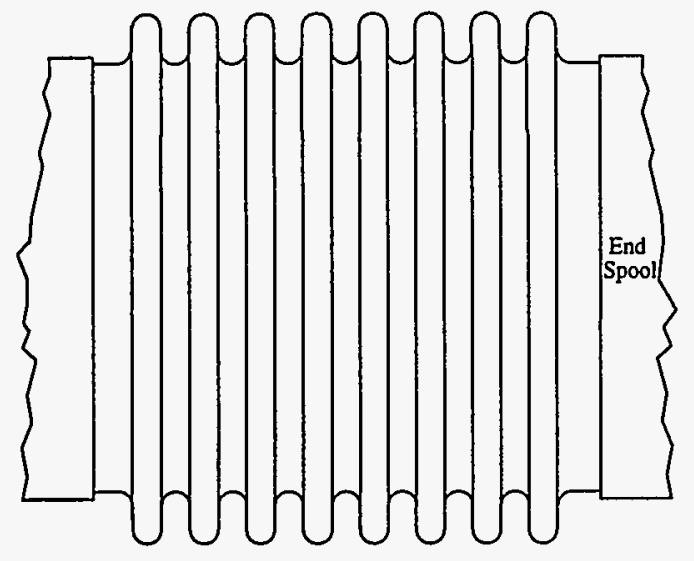

Single Element Bellows

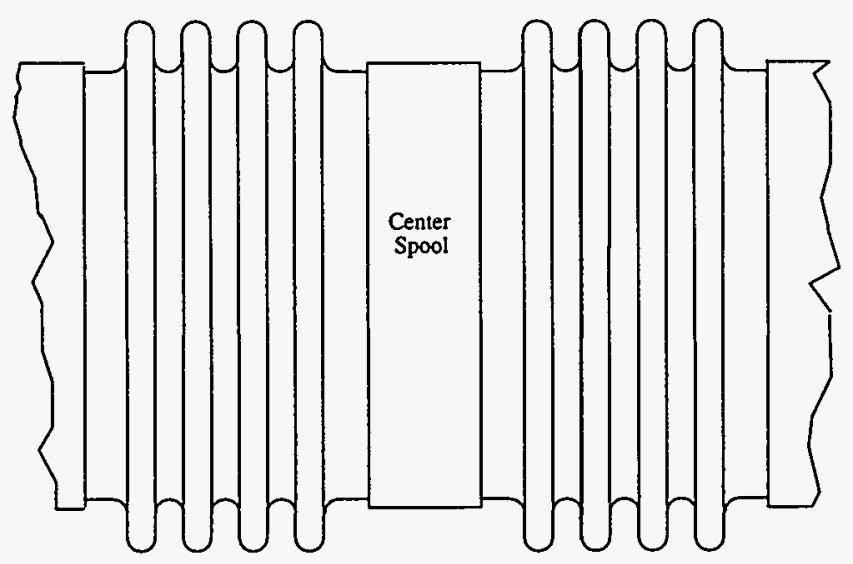

Universal Bellows

Figure 4. Bellows Configurations
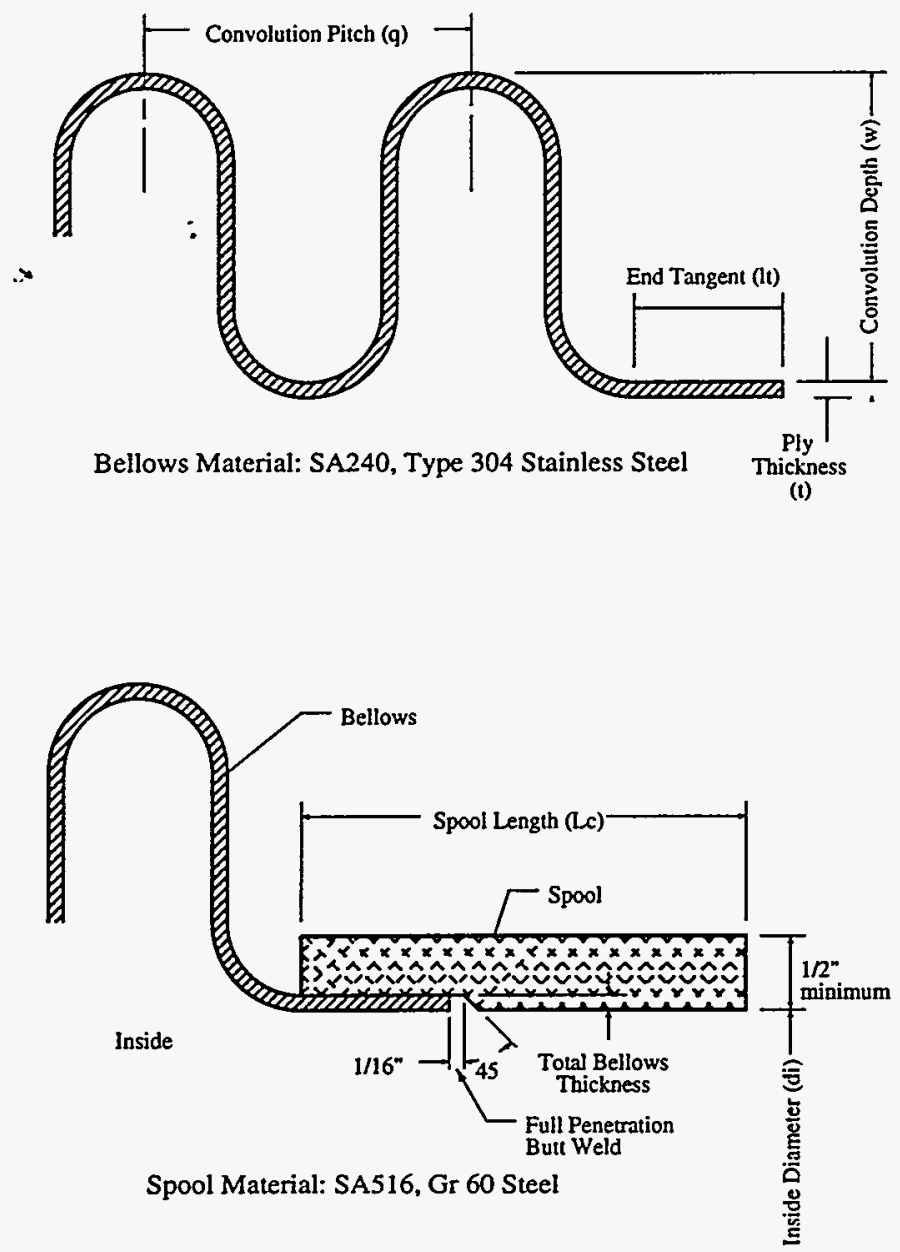

Figure 5. Definitions of Bellows Parameters 

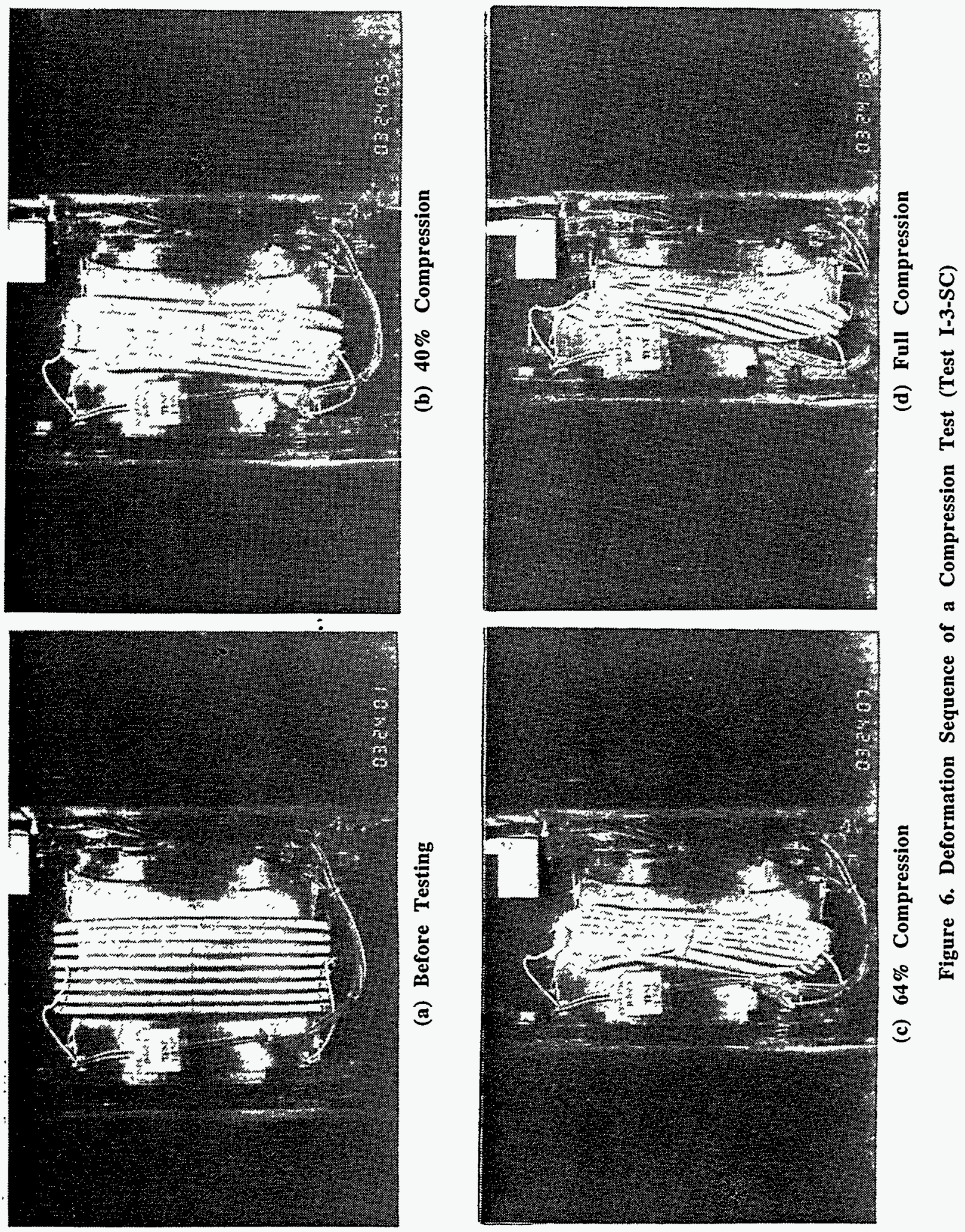


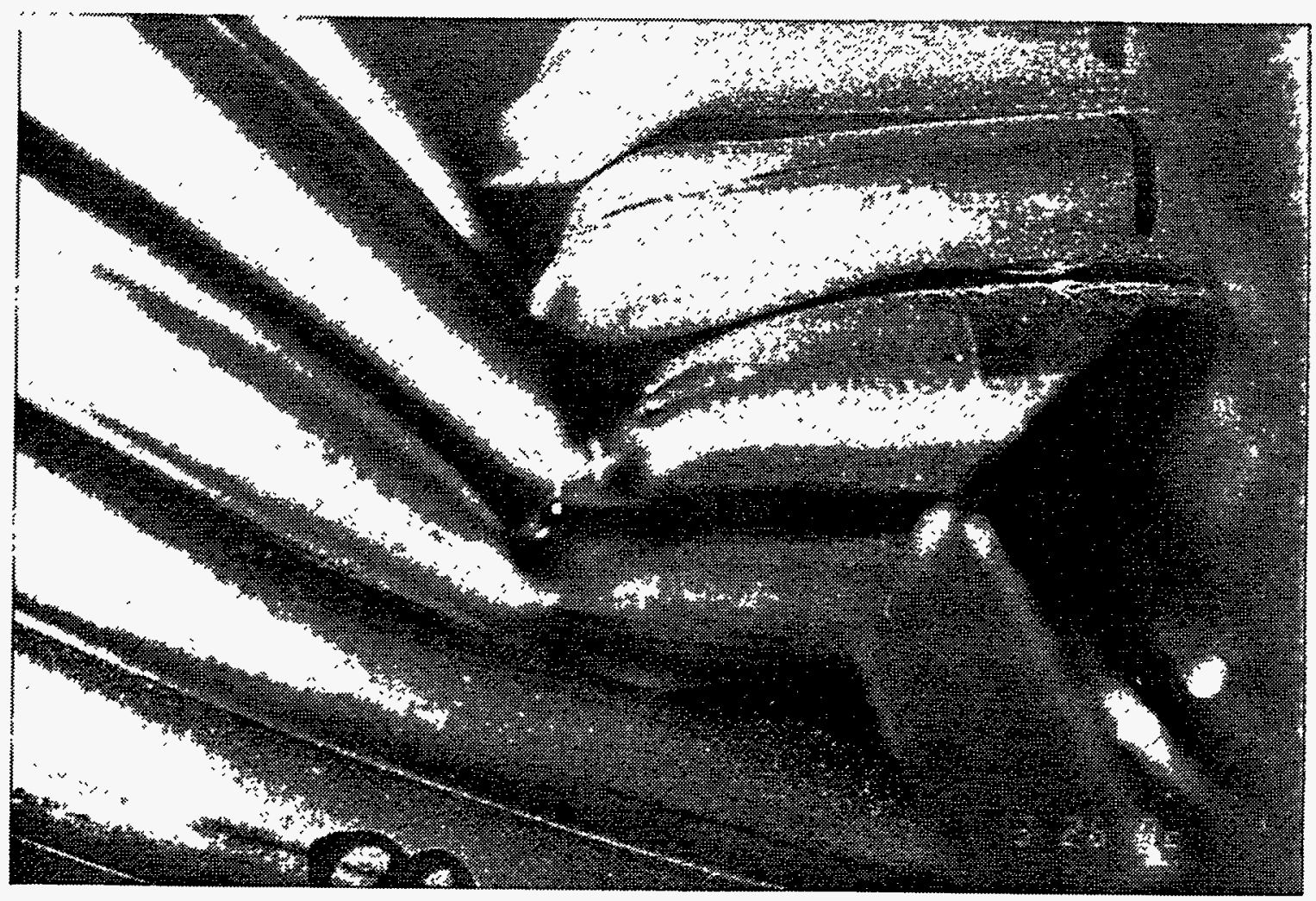

Figure 7. Close-up of Bellows Tear in Test I-3-SC

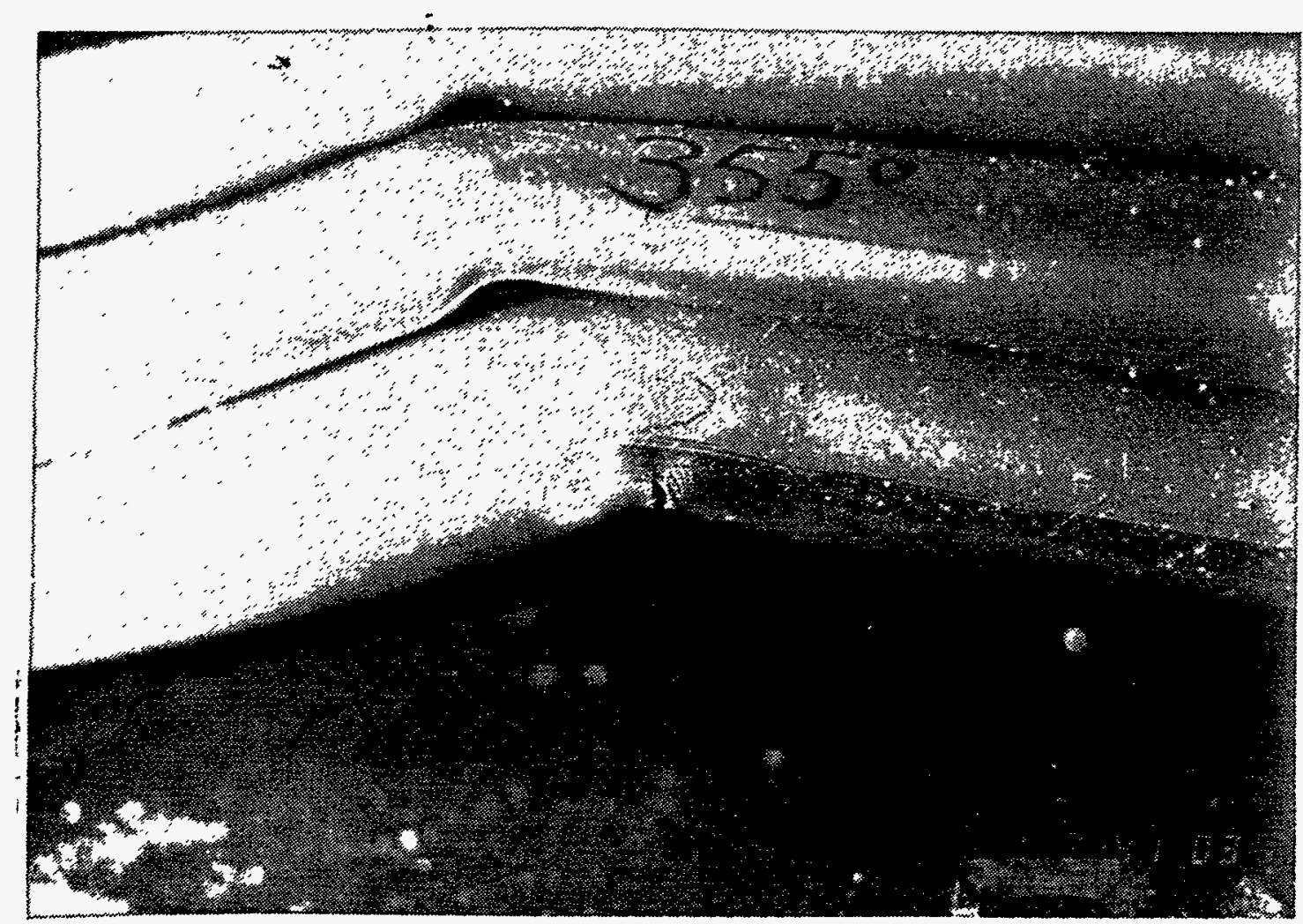

Figure 8. Close-up of Bellows Tear in Test II-17 

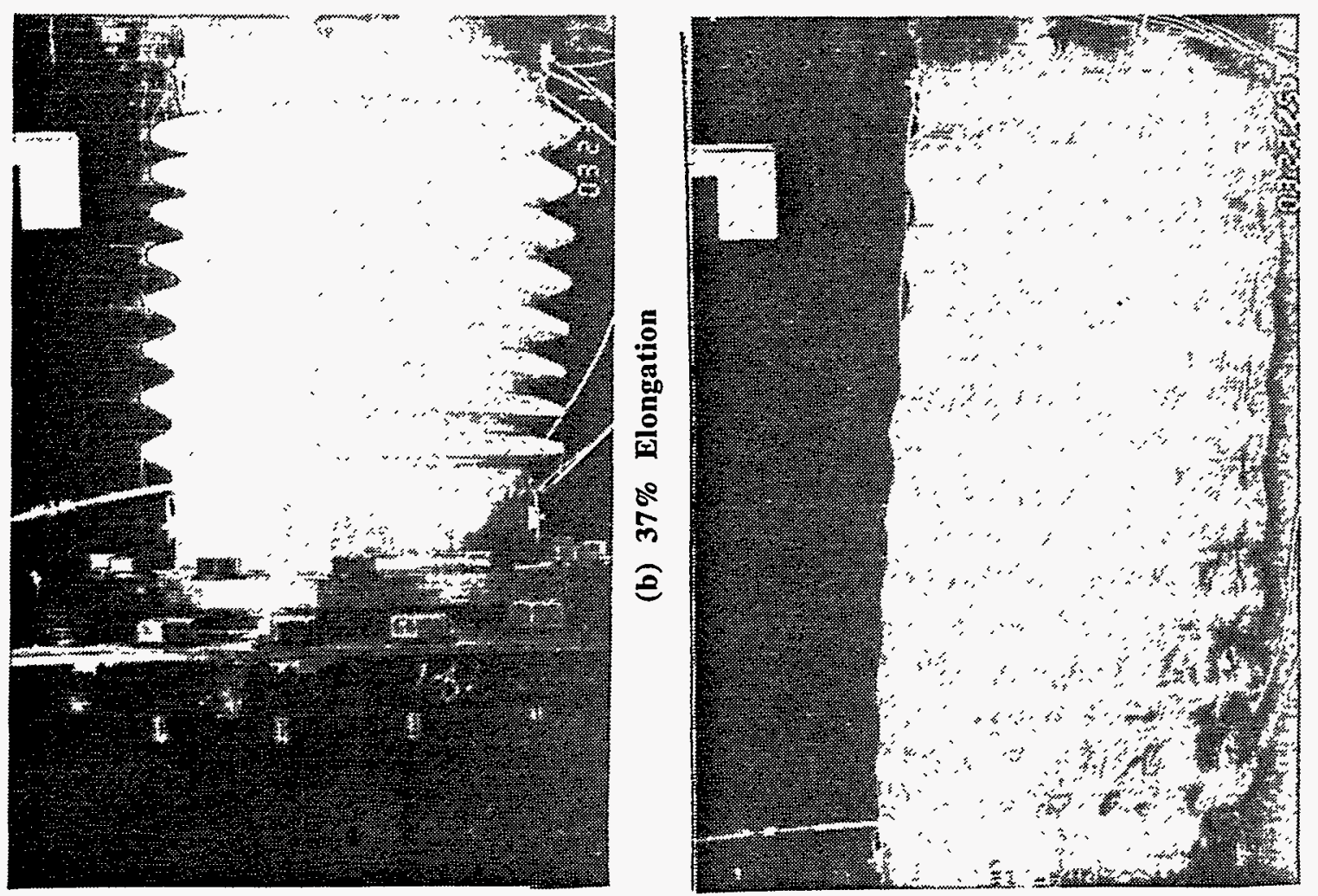

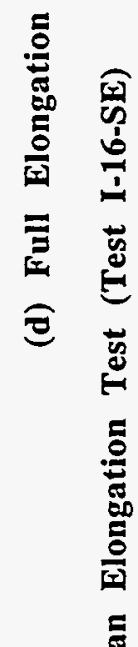
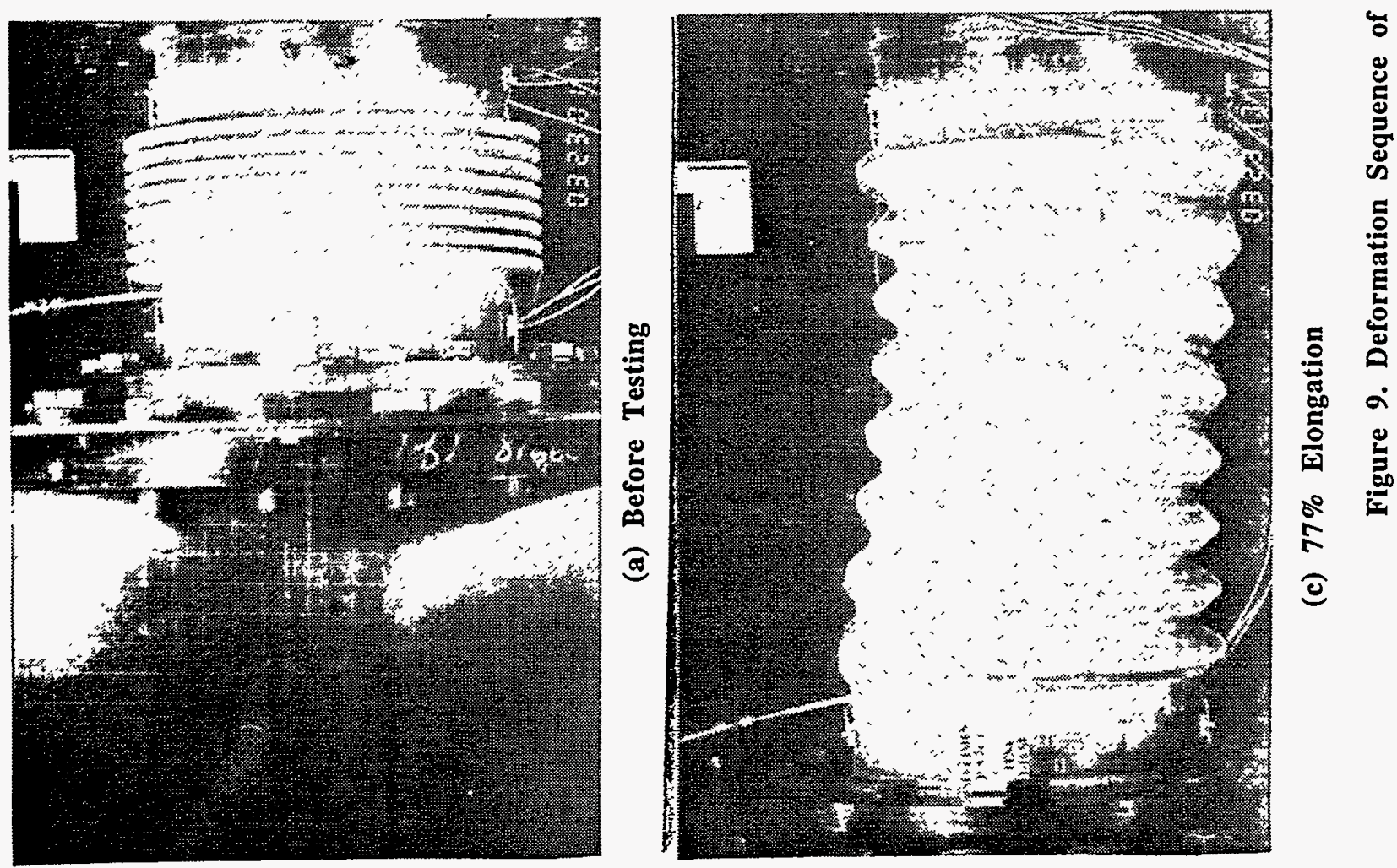


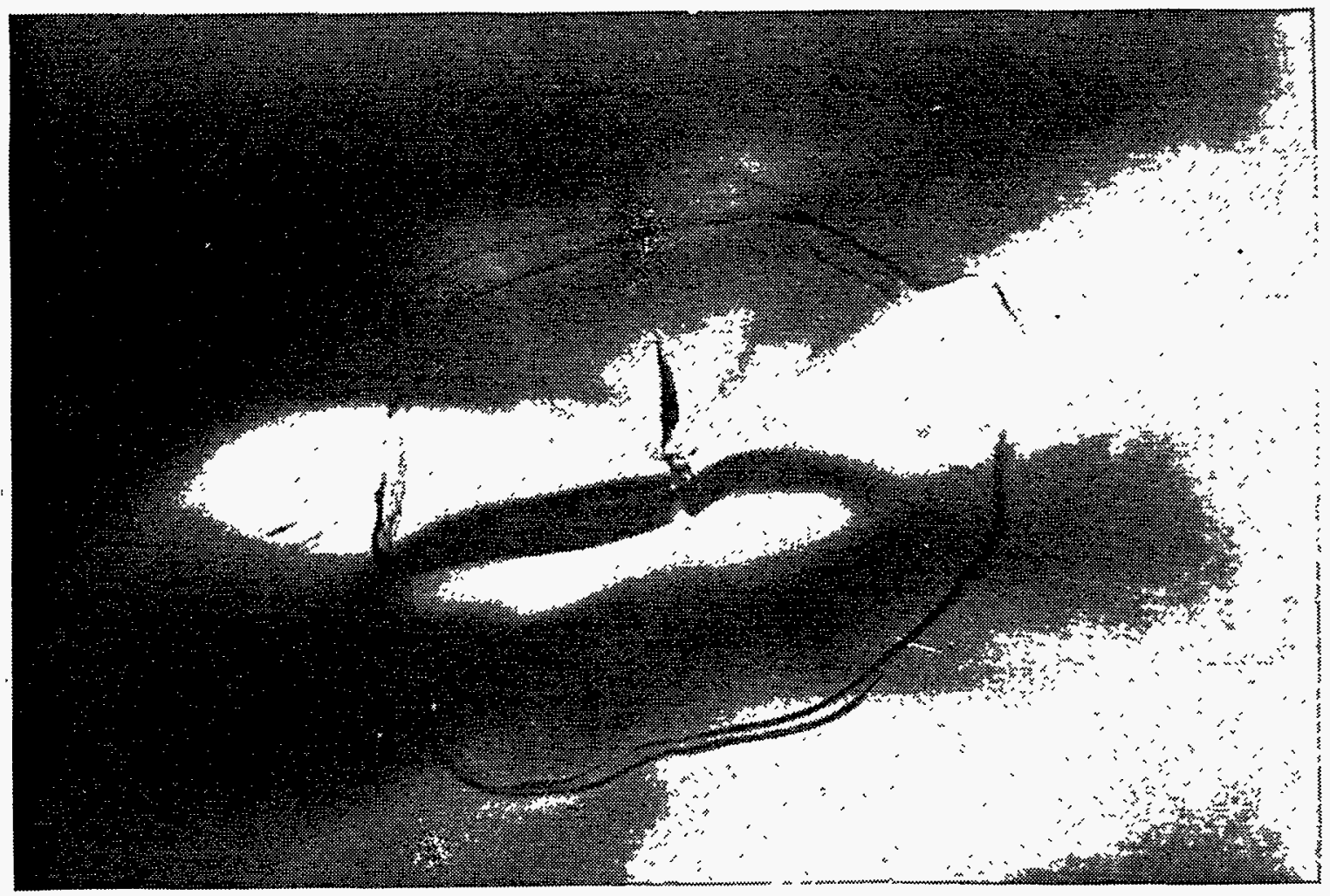

Figure 10.:Close-up of Bellows Tear in Test I-16-SE 